\title{
Pneumatic drying of cassava starch: numerical analysis and guidelines for the design of efficient small-scale dryers
}

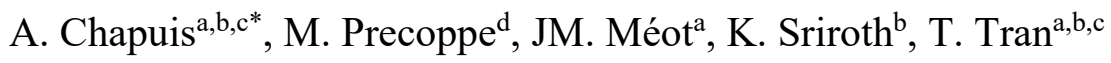 \\ ${ }^{a}$ CIRAD, UMR QualiSud, F-34398, Montpellier, France \\ ${ }^{b}$ CIRAD, UMR Qualisud, TH 10900, Bangkok, Thailand \\ ${ }^{c}$ Cassava Science and Technology Research Unit (CSTRU), Kasetsart University, TH 10900, Bangkok, Thailand \\ ${ }^{d}$ International Institute of Tropical Agriculture (IITA), Dar es Salaam, Tanzania \\ * Corresponding author: CIRAD, UMR Qualisud, TA B95/16, 73 rue Jean-François Breton, \\ 34398 Montpellier Cedex 5, France. Tel: +33 6262152 38, Tel (2): +66 85923 7351, E- \\ mail: arnaud.chapuis@mines-albi.fr
}

\begin{abstract}
In tropical countries, the expansion of cassava processing is tied to the development of smallscale, energy-efficient pneumatic dryers for flour and starch. To address this issue, a model of the pneumatic drying of starch particles was developed and fitted to measurements from large factories. Then, numerical simulations were performed to analyse the effects of geometry and operating conditions on the energy efficiency and the pipe length required to dry the product. The results clarified the influence of processing capacity, air inlet conditions, and starch particle size emphasizing that the air velocity and the dilution of starch should be minimised. Accordingly, we proposed guidelines for the design of efficient small-capacity flash dryers.
\end{abstract}

\section{Keywords}

Cassava starch - Pneumatic dryer - Modelling - Design guidelines - Energy efficiency 


\section{Nomenclature}

\section{Variables}

$A_{\mathrm{p}} \quad\left[\mathrm{m}^{2}\right] \quad$ Particle surface

$A_{\mathrm{p}}{ }^{\prime} \quad\left[\mathrm{m}^{2}\right] \quad$ Projected area of a particle

C $\quad\left[\mathrm{kg} \cdot \mathrm{m}^{-3}\right] \quad$ Volume concentration of water

$C_{p} \quad\left[\mathrm{~J} \cdot \mathrm{kg}^{-1} \cdot \mathrm{K}^{-1}\right] \quad$ Heat capacity

$C_{D} \quad[-] \quad$ Drag coefficient

$d \quad[\mathrm{~m}] \quad$ Particle diameter

$D \quad[\mathrm{~m}] \quad$ Pipe diameter

$D_{\text {ws }} \quad\left[\mathrm{m}^{2} \cdot \mathrm{s}^{-1}\right] \quad$ Diffusivity of water in starch

$\varepsilon \quad[-] \quad$ Void fraction of the bed of particles

$f \quad[-] \quad$ Coefficient of friction with the pipe wall

$g \quad\left[\mathrm{~m} \cdot \mathrm{s}^{-2}\right] \quad$ Acceleration of gravity

$h \quad\left[\mathrm{~W} \cdot \mathrm{m}^{-2} \cdot \mathrm{K}^{-1}\right] \quad$ Convection coefficient (or specific enthalpy $\left[\mathrm{J} \cdot \mathrm{kg}^{-1}\right]$ where specified)

$L_{\mathrm{s}} \quad\left[\mathrm{J} \cdot \mathrm{kg}^{-1}\right] \quad$ Net isosteric heat of desorption of water from starch

$L_{\text {pipe }} \quad[\mathrm{m}] \quad$ Total length of the drying pipe

$\dot{m} \quad\left[\mathrm{~kg} \cdot \mathrm{s}^{-1}\right] \quad$ Mass flow rate

$p_{\mathrm{v}} \quad[\mathrm{Pa}] \quad$ Water vapour pressure

$p_{\text {sat }} \quad[\mathrm{Pa}] \quad$ Saturation vapour pressure of water

$\dot{q} \quad\left[\mathrm{~W} \cdot \mathrm{m}^{-2}\right] \quad$ Heat flux from the air to the particle

$\dot{Q}_{\text {loss }}\left[\mathrm{W} \cdot \mathrm{m}^{-1}\right] \quad$ Heat loss through the pipe wall per meter of pipe

$Q_{\mathrm{s}} \quad\left[\mathrm{kJ} \cdot \mathrm{kg}^{-1}\right.$ of $\left.\mathrm{w}\right]$ Specific heat consumption

$r \quad[\mathrm{~m}] \quad$ Radial position within a particle 


$\begin{array}{lll}\rho & {\left[\mathrm{kg} \cdot \mathrm{m}^{-3}\right]} & \text { Density } \\ S & {\left[\mathrm{~m}^{2}\right]} & \text { Section of the drying pipe } \\ t & {[\mathrm{~s}]} & \text { Time } \\ T & {[\mathrm{~K}]} & \text { Temperature } \\ u & {\left[\mathrm{~m} \cdot \mathrm{s}^{-1}\right]} & \text { Velocity } \\ V_{\mathrm{p}} & {\left[\mathrm{m}^{3}\right]} & \text { Volume of a particle } \\ \dot{w} & {\left[\mathrm{~kg} \cdot \mathrm{m}^{-2} \cdot \mathrm{s}^{-1}\right]} & \text { Water mass flux from particle to air, called drying rate } \\ X & {\left[\mathrm{~kg} \cdot \mathrm{kg}^{-1} \mathrm{ds}\right]} & \text { Particle moisture content on dry basis (d.b.) } \\ Y & {\left[\mathrm{~kg} \cdot \mathrm{kg}^{-1} \mathrm{da}\right]} & \text { Air moisture content on d.b. }\end{array}$

Indices and subscript

a Moist air

da Dry air

ds Dry starch particle

i Initial state (dryer inlet)

f Final state (dryer outlet)

p Wet starch particles

v Water vapour

w Liquid water 


\section{Introduction}

\subsection{The stakes in the development of cassava starch industry}

In several tropical countries, there is a growing interest in the development of cassavaprocessing industry, which is essential to increase the economic valorisation of existing cassava roots production $[1,2]$. This trend has particularly intensified since the food crisis in 2008, stressing the need to support local agriculture and reduce the reliance on imported staple food, thereby limiting the exposure to price fluctuations on international markets and improving food security at national level. Traditionally, the cassava roots are consumed fresh as food or processed into starch, flour and other derived products. Its main drawback is its very poor conservation ability: after harvest, roots must be processed within two days; otherwise they spoil [2]. Therefore, the development of reliable technologies is a key factor in making cassava processing a profitable activity.

Thailand is the world's first exporter of cassava starch thanks to a well-structured sector and modern factories using state-of-the-art processing technologies. The roots are produced by smallholders, mostly as a cash crop, and are sold to factories producing native and modified starches that are used in many industries including paper, food, oil and gas, and more. The production of cassava starch in Thailand is carried on large scale, with a typical production capacity of factories of 200 tons of starch per day (at $0.14 \mathrm{~kg} \cdot \mathrm{kg}^{-1}$ moisture content dry basis) from 800 tons of roots, running $24 \mathrm{~h}$ a day [3]. This involves well-organised supply and distribution logistics, which can rely on a solid transport infrastructure and makes the Thai starch industry highly competitive.

By contrast, several African and South American countries have processed cassava roots into starch, flour and other products distributed on local markets for decades [4]. However, the traditional processes in use are rather limited in production capacity and the product quality is 
highly variable. Therefore, the implementation of more advanced processing technologies is expected to increase the quantity and quality of cassava products on local markets and potentially targeting the international market. It is an opportunity to enhance the benefits generated from cassava, an already well-known and widespread crop.

Consequently, the local operators try to modernise their processing equipment following the example of large-scale factories. However, the downscaling of pneumatic dryers, used at the end of the production process, remains a major difficulty. Drying is the most energydemanding operation in the process and its control is crucial to ensuring high quality of the product. Thus, the present work aims to contribute to the development of efficient drying equipment in response to the needs of small cassava processors in developing countries. The challenge consists in building small-capacity dryers with reasonable dimensions, yet energyefficient and able to deliver a product of high quality.

\subsection{Pneumatic conveying drying of starch}

The common process for producing cassava starch consists in a series of operation aiming to extract and separate the starch from the fibres contained in the roots. The roots are first finely crushed using raspers to unbind the starch granules from the root matrix. Then, the mash is dispersed in water and the starch is separated from the fibres by centrifugal sieving. Finally the water is mechanically removed by settling, centrifugation or hydro-cyclones, producing a crumbly starch cake at a moisture content of $0.55-0.60 \mathrm{~kg} \cdot \mathrm{kg}^{-1} \mathrm{ds}$, which is sent to the dryer $[3]$.

A pneumatic conveying dryer, also called flash dryer, works on the principle of an entrained fluidised-bed. The wet starch is introduced in a hot air stream using a feeding device such as a hammer-mill to break the sticky material into fine particles. Then, the particles are entrained by the hot air, dried along the pipe, and are then separated using cyclones. The 
industrial dryers in operation in Thailand have daily capacities ranging from 100 to 400 tons of dry starch using drying pipes with a diameter of about 1-2 $\mathrm{m}$ and a total length in the range of 40-60 m. The drying air temperature is generally $170-180{ }^{\circ} \mathrm{C}$ at inlet and the air velocity in the range of $15-25 \mathrm{~m} \cdot \mathrm{s}^{-1}$. The airflow is generated by suction through the drying pipe using a blower set at the air exhaust. This setting provides a slight negative operating pressure, preventing the blowing of starch dust in case of leakage.

The target moisture content for the product ranges from $0.13-0.15 \mathrm{~kg} \cdot \mathrm{kg}^{-1} \mathrm{ds}$. A major constraint to preserve the quality of the product is to avoid the gelatinisation of starch during drying: this phase change occurs when the temperature is above $60{ }^{\circ} \mathrm{C}$ and the moisture above $0.35 \mathrm{~kg} \cdot \mathrm{kg}^{-1} \mathrm{ds}$. To ensure the homogeneity of product quality despite the fluctuation of input parameters such as air and starch moisture content, the process requires continuous control. In most cases, the blower and boiler are operated at fixed load while the outlet air temperature is maintained stable around $50-55^{\circ} \mathrm{C}$ by controlling the starch feed rate.

By contrast, the smaller starch producers in other countries aim for daily capacities of 210 tons of starch and have built dryers using pipes in the range of $10-15 \mathrm{~m}$ long. They tend to use similar operating conditions as large factories, with slightly lower air velocity. However, common problems are insufficient drying and, when target moisture is achieved, high energy consumption levels and product quality issues due to gelatinisation. Actually, a range of factors affects the performance of a flash dryer, from the drying pipe design (dimensions) to the operating conditions including the air temperature and velocity and the feed rate.

\subsection{Modelling and numerical analysis of flash drying}

The modelling of heat and mass transfer in the dryer can provide a better understanding of the process and allow to identify the parameters governing the performance. The modelling of flash drying is largely covered in the scientific literature since this process is used for a range 
of powder materials, including PVC, silica [5], alumina [6, 7], limestone [8], sawdust [9] and food products such as rice powder and other starchy products [10-12]. Though, no specific work was published on the design of flash dryers for cassava starch.

In this paper, we propose to use modelling to help understand the influence of design and operating parameters on the performances of flash drying and to analyse the possibilities for downscaling the process. First, we built a mathematical model to describe and simulate the drying of starch particles. The model was based on previously published articles about the drying of potato starch and rice powder $[10,11]$, although with a major difference in the assumptions: while the previous authors considered the drying was convection-driven, we considered that it is diffusion-driven. Then, the model was fitted to plant data from five industrial producers of cassava starch in Thailand and Paraguay.

Finally, a major novelty of this work is the use of numerical analysis to determine guidelines for the design of small-scale flash dryers of high energy-efficiency, yet with reasonable dimensions. To this purpose, we performed a series of simulations to analyse the trade-off between pipe length and specific energy efficient consumption, under various operating conditions. The results clarified the effects of design and operating parameters and lead to the proposition of guidelines for the design of energy-efficient dryers.

\section{Drying model description}

\subsection{Drying mechanism and modelling assumptions}

A one-dimensional incremental model was applied to describe the changes of moisture, temperature and velocity of air and particles along the dryer. This type of model already proved successful in simulating the pneumatic drying of particles [7, 9-11, 13]. Moreover, it 
provides appropriate levels of details and accuracy for dryer design purposes and still requires far less computing time than CFD models [14].

Pelegrina and Crapiste (2001) [10] proposed a mathematical model for the pneumatic drying of food particles that was later improved and used by Tanaka et al. (2008) [11] to study the drying of rice powder. In the present work, the same overall balance equations were used, but with different assumptions concerning the physical mechanisms driving the drying at particle level.

The drying of a particle in a flash dryer occurs through two mass transfer mechanisms in series: the diffusion of water from the inside to the surface of the particle and the convective transfer from the surface to the air. The slowest mechanism determines the maximum drying rate. The Biot number compares the relative resistance to water transport of diffusion and convection [15]. In the case of starch particle drying, the Biot number is of the order of magnitude of $10^{5}$, which indicates that the drying rate is entirely governed by the kinetics of water diffusion. Practically, it means that when a starch particle enters the drying pipe, its surface dries almost instantaneously to the equilibrium moisture with the surrounding air. In turn, the moisture gradient created within the particle causes the water to migrate from the centre to the surface.

Eventually, the size of starch particles is heterogeneously distributed with diameter ranging from $50 \mu \mathrm{m}$ to $450 \mu \mathrm{m}$. It is highly variable depending on moisture content and feeding system and it continually changes as particles may agglomerate or split during drying [16]. The description of these phenomena within the drying model would be prohibitive due to its complexity. Moreover, as the measurement of this property is very difficult, almost no experimental data is available in the literature. 
Thus, as a simplifying assumption, the particles were considered spherical and homogeneous in size: during drying, they keep a constant volume while their porosity increases (see section 2.4). The drying is therefore modelled identically for all particles while in reality, it is likely that all particles do not dry at the same rate and the moisture equilibrates afterwards. The consequence of this assumption is that the particle diameter in the model should be considered as a parameter equivalent to the actual particle size distribution. Its value may vary from a dryer to another as the result of different feeding systems. The main drawback of this method is that the possible effects of operating conditions on particle size are not modelled.

Then, five industrial starch dryers were simulated with the model to evaluate the value range of particle diameter. Based on simulations, the particle diameter was chosen so that the model output matched the manufacturer data in terms of starch outlet moisture, which is the most sensitive output variable. This is further detailed in section 4.1.

\subsection{Overall balance equations}

The method for modelling such drying operation consists in balancing the exchanges between the starch and the drying air in terms of mass, momentum and heat [17]. The resolution of balance equations allows to calculate the moisture, velocity and temperature profiles of air and starch particles along the drying tube. This section presents the one-dimensional balance equations, originally proposed by Pelegrina and Crapiste (2001) [10]. The physical and thermodynamic properties of moist air were retrieved from the following references: $[15,18-$ 20]. 


\subsubsection{Momentum balance}

The momentum balance for a single particle is given by equation (1), while equation (2) refers to the drying air in a control volume (portion of the drying pipe defined as $u_{\mathrm{a}} \cdot S \cdot d t$ ).

$$
\begin{gathered}
\frac{d u_{\mathrm{p}}}{d t}=\dot{u}_{\mathrm{p}}=\frac{A_{\mathrm{p}}{ }^{\prime}}{2 V_{\mathrm{p}}} \cdot C_{\mathrm{D}} \cdot \frac{\rho_{\mathrm{a}}}{\rho_{\mathrm{p}}} \cdot\left(u_{\mathrm{a}}-u_{\mathrm{p}}\right) \cdot\left|u_{\mathrm{a}}-u_{\mathrm{p}}\right| \pm\left(1-\frac{\rho_{\mathrm{a}}}{\rho_{\mathrm{p}}}\right) \cdot g-\frac{f_{\mathrm{p}} \cdot u_{\mathrm{p}}^{2}}{2 D} \\
\frac{d u_{\mathrm{a}}}{d t}=\dot{u}_{\mathrm{a}}=-\frac{1}{\rho_{\mathrm{a}} \cdot u_{\mathrm{a}}} \cdot \frac{d P}{d t} \pm g-\frac{4 \cdot f_{\mathrm{a}} \cdot u_{\mathrm{a}}^{2}}{2 D}-\frac{A_{\mathrm{p}}{ }^{\prime}}{2 V_{\mathrm{p}}} \cdot C_{\mathrm{D}} \cdot \frac{1-\varepsilon}{\varepsilon} \cdot\left(u_{\mathrm{a}}-u_{\mathrm{p}}\right) \cdot\left|u_{\mathrm{a}}-u_{\mathrm{p}}\right|
\end{gathered}
$$

The drag coefficient is calculated using the correlation proposed by Schiller and Naumann (1935) [21]. The pipe is made of drawn stainless steel, so the air-wall friction coefficient is calculated using the Blasius correlation for smooth pipes [17]. The particle-wall friction coefficient is calculated using the experimental correlation from Capes and Nakamura (1973) [22].

The void fraction $\varepsilon$, defined as the volume ratio of air to total volume, is used to couple the solid-phase and gas-phase balance equations. It can be expressed using the mass balance equations of air and particles, as in equation (3).

$$
\frac{\dot{m}_{\mathrm{da}} \cdot(1+Y)}{\rho_{\mathrm{a}}}=u_{\mathrm{a}} \cdot S \cdot \varepsilon
$$

To solve the momentum and mass balance equations, the dry air and dry starch mass flow rates are set as constant. The initial particle velocity cannot be set to zero because this would be inconsistent with the one-dimensional model (if velocity $=0$, flow rate $=0$ ). Instead, the initial particle velocity is set to a slightly positive value, small compared to the air velocity, e.g $0.5 \mathrm{~m} \cdot \mathrm{s}^{-1}$. 


\subsubsection{Heat balance}

Equations (4) and (5) give the heat balance related to a particle and to the drying air respectively.

$$
\begin{gathered}
\frac{d T_{\mathrm{p}}}{d t}=\frac{A_{\mathrm{p}}}{V_{\mathrm{p}}} \cdot \frac{1}{\rho_{\mathrm{p}} \cdot C_{\mathrm{p}}^{\mathrm{p}}} \cdot\left(\dot{q}-\dot{w} \cdot L_{\mathrm{s}}\right) \\
\frac{d T_{\mathrm{a}}}{d t}=-\frac{1}{C_{\mathrm{p}}^{\mathrm{a}}} \cdot\left(\frac{A_{\mathrm{p}}}{\rho_{\mathrm{a}} \cdot V_{\mathrm{p}}} \cdot \frac{1-\varepsilon}{\varepsilon} \cdot\left(\dot{q}+\dot{w} \cdot C_{\mathrm{p}}^{\mathrm{v}} \cdot\left(T_{\mathrm{a}}-T_{\mathrm{p}}\right)\right)+\frac{\dot{Q}_{\mathrm{loss}} \cdot u_{\mathrm{a}}}{\dot{m}_{\mathrm{da}} \cdot(1+Y)}\right)
\end{gathered}
$$

The temperatures of air and particles are considered homogeneous and are respectively set to $T_{\mathrm{a}}^{\mathrm{i}}$ and $T_{\mathrm{p}}^{\mathrm{i}}$ at initial state.

The heat losses to the environment occur by heat transfer through the pipe wall. They are estimated by calculating the heat flux through the pipe wall including internal and external convection and conduction through the pipe insulation. Following the information provided by starch factories, the pipes are generally made of $2 \mathrm{~mm}$ thick stainless steel with a conductivity of $16.3 \mathrm{~W} \cdot \mathrm{m}^{-1} \cdot \mathrm{K}^{-1}$, often insulated with a layer of rock wool, with a conductivity of $0.04 \mathrm{~W} \cdot \mathrm{m}^{-1} \cdot \mathrm{K}^{-1}$. The internal convective transfer coefficient is calculated using the SiederTate correlation [15] and the free convection coefficient to the ambient is set to an average value of $15 \mathrm{~W} \cdot \mathrm{m}^{-2} \cdot \mathrm{K}^{-1}[23]$.

\subsubsection{Water mass balance}

The water mass balance is expressed by equation (6) and (7), giving the variations of moisture contents with time, of starch and air respectively.

$$
\frac{d X}{d t}=\dot{X}=-\frac{A_{\mathrm{p}} \cdot \dot{w}}{V_{\mathrm{p}} \cdot \rho_{\mathrm{p}}} \cdot(1+X)
$$




$$
\dot{Y}=-\dot{X} \cdot \frac{\dot{m}_{\mathrm{ds}}}{\dot{m}_{\mathrm{da}}}
$$

The air moisture is considered as homogeneous, while the moisture profile within the particle is calculated by solving diffusion equation as discussed in the following section.

\subsection{Water and heat transfer at particle level}

In addition to the overall balance equations, local models are required to evaluate the heat and mass exchanges at particle level. The resolution of these local models provides the heat and mass flux terms, $\dot{q}$ and $\dot{w}$, required in the overall balance.

\subsubsection{Diffusion-driven water mass transfer}

According to the assumption of diffusion-driven drying, the drying rate $\dot{w}$ is governed by the dynamics of diffusion at particle level. The transport of water from the centre to the surface of starch particles combines several mechanisms including vapour and liquid diffusion, capillary flows and surface diffusion. This was modelled using the $2^{\text {nd }}$ Fick's law with an effective diffusivity coefficient [24], which includes the effects of all the mechanisms involved. The effective diffusivity of water in starch was evaluated as a function of temperature and water concentration as proposed by Karathanos et al. (1991) [25]. Therefore, the diffusivity is temporally and spatially dependent. Assuming that the diffusion properties of water in starch are isotropic, the diffusion equation is expressed in spherical coordinate with spherical symmetry in equation (8).

$$
\frac{\partial C}{\partial t}=\frac{1}{r^{2}} \cdot \frac{\partial}{\partial r} \cdot\left(r^{2} \cdot D_{w s}\left(C, T_{p}\right) \cdot \frac{\partial C}{\partial r}\right)
$$

At initial state, the moisture is homogeneously distributed within the particle. After the introduction of the particle in the drying pipe, the particle surface is instantaneously in 
equilibrium with the surrounding air, i.e. the water vapour pressure at the particle surface is equal to the vapour pressure in the surroundings. Knowing the vapour pressure and the particle surface temperature, the water activity $a_{\mathrm{w}}$ can be deduced using equation (9).

$$
a_{\mathrm{w}}=\frac{p_{\mathrm{v}}(Y)}{p_{\mathrm{sat}}\left(T_{p}\right)}
$$

where $p_{\mathrm{v}}(Y)$ and $p_{\text {sat }}\left(T_{\mathrm{p}}\right)$ are the vapour pressure in air and the saturation vapour pressure at the particle surface temperature respectively.

The water activity at the surface of a product can be related to its moisture content at a given temperature using sorption isotherms. No specific sorption data were found in the literature for cassava starch at the temperature range of the process. Therefore, we used the sorption isotherm of high-amylopectin starch at $45^{\circ} \mathrm{C}$, as proposed by Al-Muhtaseb et al. (2004) [26]. This assumption is justified by the fact that cassava starch is mostly composed of high amylopectin. Moreover, according to [26], the sorption properties of high-amylopectin and high-amylose starch are very close.

The sorption isotherm is described using a GAB model, i.e. $X_{\mathrm{p}}=f\left(a_{\mathrm{w}}\right)$. Knowing the water activity at the particle surface the GAB relation is used to calculate the starch moisture content at the particle surface, providing the boundary condition required to solve the diffusion equation. The resolution of water diffusion in the particles allows to calculate the drying rate, which is the water mass flux density at the surface of the particle.

\subsubsection{Convection-driven heat transfer}

As for water mass transfer, the transfer of heat between the air and the particle occurs through convection and conduction modes in series. In order to identify the governing transfer mechanism, the Biot number for heat transfer was evaluated at several positions along the 
drying pipe, using the data on the thermal conductivity of granular starch provided by Drouzas and Saravacos (1988) [27]. As the conductivity of starch strongly increases with bulk density and moisture, the Biot number remains relatively low $(\leq 0.1)$ throughout the drying pipe, indicating that the heat conduction within the particle is relatively fast and that the transfer is mostly controlled by convection at the interface $[15,28]$. Therefore, the temperature of the particles is considered homogeneous.

The convective heat flux is calculated according to equation (10), using the convective heat exchange coefficient $h$. A modified version of the common Ranz-Marshall correlation, specifically developed for drying particles, was used to evaluate $h$ as recommended in $[13,14$, 29].

$$
\dot{q}=h \cdot\left(T_{\mathrm{a}}-T_{p}\right)
$$

\subsection{Starch particles properties}

Owing to their structure (agglomerated granules), starch particles are porous materials and their bulk density should be expressed as a function of porosity [30]: $\rho_{\mathrm{b}}=\left(1-\varepsilon_{\mathrm{p}}\right) \cdot \rho_{\mathrm{s}}$ where $\varepsilon_{\mathrm{p}}$ is the porosity of the particle, and $\rho_{\mathrm{s}}\left[\mathrm{kg} \cdot \mathrm{m}^{-3}\right]$ is the solid density.

Marousis and Saravacos (1990) [31] and Karathanos and Saravacos (1993) [30] have studied the density and porosity of starch materials during drying and observed that the porosity of starch increased linearly during drying. Following Marousis and Saravacos (1990) [31], the solid density of starch granules, may be expressed as a function of moisture content using equation (11).

$$
\rho_{\mathrm{s}}(X)=1442+837 \cdot X-3646 \cdot X^{2}+4481 \cdot X^{3}-1850 \cdot X^{4}
$$


Based on the same work, the porosity of cassava starch at the dryer inlet, i.e. moisture content within $0.5-0.6 \mathrm{~kg} \cdot \mathrm{kg}^{-1} \mathrm{ds}$, was estimated to 0.175 , by analogy with results obtained for Amioca starch.

Then, assuming no shrinkage during drying, the water evaporated during drying is replaced with air and the bulk density of particles can be calculated as a function of initial porosity and moisture as in equation (12).

$$
\rho_{\mathrm{p}}=\left(1-\varepsilon_{\mathrm{pi}}\right) \cdot \rho_{\mathrm{s}}(X) \cdot \frac{1+X}{1+X_{\mathrm{i}}}
$$

where $\varepsilon_{\mathrm{pi}}[-]$ and $X_{\mathrm{i}}\left[\mathrm{kg} \cdot \mathrm{kg}^{-1}\right]$ are respectively the porosity and moisture content of the particle at initial state.

Eventually, the heat capacity of dry starch is $1500 \mathrm{~J} \cdot \mathrm{kg}^{-1} \cdot \mathrm{K}^{-1}[32]$. The heat capacity of humid starch particles is calculated as the mass fraction average of pure starch and pure water heat capacities. In absence of specific data for granular cassava starch, the heat of sorption was calculated based on highly amylopectin and highly amylose starches data provided by AlMuhtaseb et al. (2004) [33] for temperatures ranging from $30{ }^{\circ} \mathrm{C}$ to $60{ }^{\circ} \mathrm{C}$ and moisture content from 0.02 to $0.2 \mathrm{~kg} \cdot \mathrm{kg}^{-1} \mathrm{ds}$.

\subsection{Model implementation}

The model was implemented using Matlab ${ }^{\circledR}$ (MathWorks, Natick, MA). The mass, momentum and energy balance equations were solved using a fourth-order Runge-Kutta integration method. At each time-step, the partial differential equation of diffusion (8) is solved using a finite element explicit method, thus providing the water concentration profile within the particles, as proposed by [28]. The discretisation scheme for equation (8) was recommended by Ford Versypt and Braatz (2014) [34] who conducted a detailed analysis of the precision and stability of different discretisation schemes for diffusion problems with 
variable diffusivity in spheres.

The stability of such resolution method depends on the time and spatial steps chosen. In the present case, the relation $N<\frac{R_{0}}{\sqrt{2 \cdot D \cdot d t}}$, where $\mathrm{N}$ is the number of grid points $\mathrm{D}$ the diffusivity and $\mathrm{R}_{0}$ the radius of the sphere, should be verified. As an indication, with $d t=10^{-}$ ${ }^{4} \mathrm{~s}, R_{0}=200 \mu \mathrm{m}, \mathrm{D}=10^{-9} \mathrm{~m}^{2} \cdot \mathrm{s}^{-1}$, the maximum number of grid points is $N=224$. Using more grid points would require using a shorter time step, hence increasing the computing time.

The precision of the resolution method was tested by comparing the results for various spatial and time steps. To consider the least favourable case, the data from dryer TH-2 (see section 4.1) was used, since it has the longest pipe and is thus, more prone to accumulation of errors. The time step was varied between $10^{-5} \mathrm{~s}$ and $10^{-4} \mathrm{~s}$, while the number of spatial grid points ranged from 50 to 250 . Over this domain, the model output in terms of starch moisture content varied by less than $1.5 \%$. For the range $N=100-250$, this variation was reduced to less than $0.5 \%$, which is precise enough for the purpose of this study. Therefore, to ensure a good precision level while keeping reasonable computing time, the number of grid points was set to $N=100$ and the time step to $d t=10^{-4} \mathrm{~s}$.

\subsection{Dryer efficiency: specific energy consumption}

An efficient dryer is a dryer that maximises the use of the sensible heat of the drying air to evaporate the water from the product. Ideally, the outlet air should be saturated with moisture and its temperature as low as possible. In the case of isenthalpic drying (free-water removal at constant temperature), the minimum outlet air temperature corresponds to the adiabatic saturation temperature [35]. A common indicator to characterize the performance of a dryer is its specific energy consumption, defined as the energy spent to evaporate $1 \mathrm{~kg}$ of water from 
the product. Its expression is given in equation (13). Its value can be compared to the latent heat of vaporisation of water at product inlet temperature.

$$
Q_{\mathrm{s}}=\frac{\dot{m}_{\mathrm{da}} \cdot\left(1+Y_{\mathrm{i}}\right) \cdot\left(h_{\mathrm{in}}-h_{\mathrm{ext}}\right)}{\dot{m}_{\mathrm{ds}} \cdot\left(X_{\mathrm{i}}-X_{\mathrm{f}}\right)}
$$

where $h_{\text {ext }}\left[\mathrm{kJ} \cdot \mathrm{kg}^{-1}\right]$ and $h_{\text {in }}\left[\mathrm{kJ} \cdot \mathrm{kg}^{-1}\right]$ are the specific enthalpy of the drying air, at ambient and dryer inlet conditions respectively.

\section{Numerical analysis method}

The model was used to assess the possibilities to improve the design of small-capacity flash dryers in view of maximising their energy efficiency, while keeping reasonable dimensions. The analysis method was based on a series of numerical simulations: it allowed to quantify the trade-off between pipe length and energy consumption while assessing the effects of various factors including inlet air conditions and processing capacity.

\subsection{Design problem description and method of analysis}

The basic functional specifications for the construction of a flash dryer are the capacity (starch feed rate) and the inlet and target moisture content, which are fixed. Then, the objective is to define a design that minimises the specific energy consumption and the length of the dryer. The design includes two aspects: the geometry of the drying pipe and the operating conditions. In the present study, we only considered constant-diameter pipes to limit the range of possible geometries. Thus, the pipe geometry was defined by two variables: the diameter and the length. The operating conditions were also defined by two variables: the inlet velocity and temperature of the drying air. Overall, 4 variables are required to define the system and, since there is the constraint that the starch outlet moisture meets the target, only three variables are independent (or degrees of freedom). 
Accordingly, when the operating conditions are fixed (air velocity and temperature), two variables remains, the pipe diameter and length, with only one degree of freedom. Thus, the pipe diameter was set as the independent variable and the model was used to calculate the pipe length required to dry the starch mass flow to the target moisture. This was achieved using a "while" loop that exits the time iterations when the starch moisture meets the target.

Note that when the inlet air velocity and temperature are fixed, the pipe diameter directly controls the air mass flow rate, and thus the dilution of starch, i.e. the ratio $\frac{\dot{m}_{\mathrm{da}}}{\dot{m}_{\mathrm{ds}}}$. Obviously, to meet the target moisture, a first condition is to ensure that the air mass flow has the capacity to absorb the moisture released by the starch. The lower bound can be calculated by assuming that the drying air undergoes an adiabatic humidification during the process, up to saturation: this gives the adiabatic air mass flow rate. Then, the second condition is that the pipe length provides a residence time long enough to allow the transfer of the starch moisture to the air. And under fixed operating conditions, the residence time, thus the pipe length, required to meet the target moisture is controlled by the dilution of starch, i.e. by the diameter of the pipe. This is explained by the fact that the dilution actually affects the gradient of vapour pressure (or "humidity") between air and particles, which is the driving mechanism of the drying. Therefore, high dilution (large diameter) will result in short pipe length and conversely.

The second objective is to minimise the energy consumption of the dryer. This is achieved when all the sensible heat in the drying air is used to evaporate the product moisture, or in other words, the exhaust air is saturated with moisture (although, in practice, condensation should be avoided). Following this theory, maximising the energy efficiency would lead to maximising the length of the drying pipe: therefore, under fixed operating conditions, there must be a trade-off between pipe length and energy efficiency. 
To analyse this trade-off, the drying model program was tuned so that it returns both the pipe length required to reach the target moisture and the energy consumption as function of pipe

diameter $\left(\left[Q_{\mathrm{s}}, L_{\text {pipe }}\right]=f[D]\right)$. This method provides all the combinations of pipe diameter and length that allow to dry a given flow rate of wet starch to the desired moisture, under given inlet conditions. By performing simulations for various inlet conditions, the effects of air velocity and air temperature were assessed. Moreover, the influence of other parameters such as the processing capacity and the particle diameter were also studied. In all simulation, the pipe was assumed vertical with upward flow, since the length is unknown beforehand.

\subsection{Default values of input parameters}

For the need of the simulations, it was necessary to define default values for all input parameters; they are presented in Table 1. As one of the main motivation of this work is to investigate the possibilities for using flash dryers in small- and medium-scale starch factories, the default processing capacity was set 2 tons of starch per day, which corresponds to a dry starch mass flow rate of $0.02 \mathrm{~kg} . \mathrm{s}^{-1}$. The default particle diameter was set to $230 \mu \mathrm{m}$, corresponding to the average of fitted diameters (see section 4.1.1). For the other parameters, mid-range values were chosen as default.

The default air velocity was varied between $10 \mathrm{~m} \cdot \mathrm{s}^{-1}$ and $20 \mathrm{~m} \cdot \mathrm{s}^{-1}$. In practice, the lower bound for air velocity is the minimum required to entrain the largest particles. According to $[36,37]$, the minimum entrainment velocity for starch particles with a diameter in the order of $230 \mu \mathrm{m}$ is smaller than $1 \mathrm{~m} . \mathrm{s}^{-1}$. Therefore, even though starch particles may agglomerate, an air velocity of $10 \mathrm{~m} \cdot \mathrm{s}^{-1}$ should be high enough to entrain the largest particles. Experimental trials would be necessary to identify the lower bound. 
Eventually, the range of the simulations (realised using the function $\left[Q_{\mathrm{s}}, L_{\text {pipe }}\right]=f[D]$ ) was bounded according the output values: only the dryers featuring a pipe length lower than 40 meters and a specific energy consumption lower than $10000 \mathrm{~kJ}^{\mathrm{kg}}{ }^{-1}$ were considered. Consequently, the variation range of pipe diameter depends on the case studied.

\section{Results and discussion}

\subsection{Model fitting using field data from large scale dryers}

In order to compare the model prediction to actual performance of cassava starch flash dryers, data were collected from 5 industrial production plants, 3 in Thailand (referred to as TH-\#) and 2 in Paraguay (referred to as PA-\#); they are summarised in Table 2. In practice, several factors influencing the drying are variable, especially the inlet air moisture content and the wet starch moisture content. This problem is overcome by continuously adjusting the starch feed rate to keep constant the air outlet temperature, using automatic control. Therefore, the information provided by the starch manufacturers, in terms of input and output conditions of air and starch, were in the form of value ranges rather than accurate values. Thus, average values were considered for the simulations.

In Thailand, the starch factories have in average larger processing capacities than in Paraguay. The dryers in Thai factories have larger dimensions, both in diameter and length. They also use higher drying air temperatures than the dryers in Paraguay (in average $173{ }^{\circ} \mathrm{C}$ vs. $143{ }^{\circ} \mathrm{C}$ ). Another significant difference between the two countries is the climate which is dryer in Paraguay, resulting in lower air inlet moisture.

Among the 5 dryers, the air inlet velocity ranges from $9.8 \mathrm{~m} . \mathrm{s}^{-1}$ to $23.8 \mathrm{~m} . \mathrm{s}^{-1}$. In terms of pipe geometry, all 5 dryers include an upward followed by a downward section. Three dryers (TH1, TH-3 and PA-1) use constant pipe diameter while in the two others (TH-2 and PA-2) the 
pipe has a change in diameter at some place. In $\mathrm{TH}-2$, there is a pipe enlargement in the downward section, which is made to increase the particles residence time by reducing air velocity. On the other hand, PA-2 has a pipe restriction right before the loop at the top of upward section. This is presumably made to raise the air velocity that may be too low at this point to entrain the particles. Indeed, the air velocity that is already relatively low at the inlet $\left(9.8 \mathrm{~m} \cdot \mathrm{s}^{-1}\right)$ decreases to $8 \mathrm{~m} . \mathrm{s}^{-1}$ in the first section of the pipe due to the important temperature decrease caused by the drying (according the simulation results).

\subsubsection{Model fitting: determination of particle size}

As mentioned in section 2.1, the particle diameter was used as a fitting parameter of the model. To this purpose, five industrial dryers were simulated using the model based the data provided by the manufacturers and taking into account the pipe geometry, including upward and downward section and diameter changes. For each of the 5 dryers, simulations were run to analyse the effects of particle diameter on process output variables. Then, based on the results of simulations, the particle diameter was fitted so that the model output matched the real data in terms of product moisture. The product moisture was used as the reference because it is the most reliable measurement available at the dryer outlet: indeed, for the starch to be marketable, its moisture content must be within a certain range, e.g. the standard in Thailand is $12-13 \%$. The air outlet temperature is also a reliable measurement since it is commonly used to control the process.

Figure 1 illustrates the variation of starch outlet moisture as a function of particle diameter, varying from $180 \mu \mathrm{m}$ to $280 \mu \mathrm{m}$, for the 5 industrial dryers. The fitted particle diameters, indicated by square markers in Figure 1 and reported in Table 3, ranges from $210 \mu \mathrm{m}$ to $245 \mu \mathrm{m}$ with an average of $227 \mu \mathrm{m}$. This shows that the approach using an average particle diameter to fit the model to field data provides consistent results. The fitted particle diameters 
are in the same range as actual starch particle diameters $(50-450 \mu \mathrm{m})$ and moreover, among 5 industrial dryers using similar technology, the variation range of fitted diameters is limited, only $\pm 8 \%$ from the average value. To go further in the validation of this approach, experimental tests would be required to verify if the fitted diameter varies with the drying conditions.

As expected, the particle size has a significant effect on the diffusion kinetics: at fixed geometry and inlet conditions, reducing the particle size results in lower outlet starch moisture. The consequences are further analysed in section 4.2.4. It should be noticed that dryer PA-2 is particularly sensitive to the variation of particle diameter. This is caused by the short length of this dryer, resulting in short residence time. This phenomenon should be taken into account when designing a dryer since this would have an impact on the flexibility of use of the equipment.

\subsubsection{Simulation results: drying profiles and energy consumption}

For the 5 dryers, simulations were run using the fitted particle diameters, in order to illustrate the profile of air and starch properties along the drying pipe and to compare the model output with the data from manufacturers; the results are presented in Table 2. The model outputs can be compared to the actual data in terms air temperature and moisture when available, as the manufacturers do not measure the other outlet parameters.

In all cases, the model output closely matches the manufacturers' data in terms of air temperature. Since the particle diameter was calibrated to match the outlet starch moisture content, the evaporated mass flow rate calculated by the model is equal to the actual value. Consequently, as the outlet air temperature depends mostly on the evaporation rate, the model outputs are close to the measured values. The thermodynamical properties of moist air being well known, the observed variations may result from errors in the evaluation of heat losses, 
heat of sorption or starch heat capacity. As an indication, the calculated heat loss for dryer TH-2 amounts to $6.7 \mathrm{~kW}$, while the power required to heat the inlet air is about 4.6 MW. Without the 2-inches rock wool insulation, the calculated heat loss is 10 times higher.

Figure 2 illustrates the profiles of air and starch properties along the pipe in the case of dryer $\mathrm{TH}-2$. When the particle enters the drying pipe, it undergoes a rapid acceleration and about 5 meters after the inlet it has reached a velocity close to that of air. The difference between air and particle velocity, termed slip velocity, is about $0.75 \mathrm{~m} \cdot \mathrm{s}^{-1}$. At $37 \mathrm{~m}$ the particle velocity becomes higher than air velocity, corresponding to the top of the drying pipe and the beginning of the downward section. The sudden drop in both air and particle velocity, at $45 \mathrm{~m}$ from pipe inlet, corresponds to a pipe enlargement from $1.5 \mathrm{~m}$ to $1.94 \mathrm{~m}$. The velocity decreases from 19 to $11 \mathrm{~m} \cdot \mathrm{s}^{-1}$, which increases the residence time of particles.

The moisture profile shows that the drying is very fast at the beginning of the pipe, because of a strong gradient of moisture and temperature. This high drying rate is accompanied by a dramatic decrease of air temperature which drops from $175^{\circ} \mathrm{C}$ to $100{ }^{\circ} \mathrm{C}$ in the first 10 meters. Alongside, the starch temperature increases progressively, rising from $35^{\circ} \mathrm{C}$ to $62{ }^{\circ} \mathrm{C}$ in the first 10 meters and then decreases progressively until the outlet. Thus, the starch remains right at the limit of gelatinisation conditions [25], (occurring around $60-70^{\circ} \mathrm{C}$ ) which is crucial to preserve the product quality. By the way, it should be noted that the temperature of starch particles during drying might be slightly over-estimated following to the assumption of homogeneous temperature.

Eventually, the specific heat consumption and the particle residence time of the dryers were calculated and are presented in Table 3 . The values of specific heat consumption range from $3060 \mathrm{~kJ} \cdot \mathrm{kg}^{-1}$ to $3800 \mathrm{~kJ} \cdot \mathrm{kg}^{-1}$, which may be compared to the latent heat of vaporisation of water at ambient temperature, $2425 \mathrm{~kJ} \cdot \mathrm{kg}^{-1}$, the theoretical minimum energy requirement for drying. Dryers TH-1, TH-2 and PA-1 are the most energy efficient with an average 
consumption of $3100 \mathrm{~kJ} \cdot \mathrm{kg}^{-1}$. This performance may be explained by the long residence time of the particles in these dryers, $3.4 \mathrm{~s}$ in average, which results from the combination of air velocity and pipe length: TH-2 uses a very long pipe $(57 \mathrm{~m})$ with relatively high velocity (24 $\left.\mathrm{m} . \mathrm{s}^{-1}\right)$, PA-1 uses a short pipe $(33 \mathrm{~m})$ with low velocity $\left(12 \mathrm{~m} \cdot \mathrm{s}^{-1}\right)$ while TH-1 uses mid-range velocity and pipe length. Eventually, PA-2 is the least efficient dryer and also the one with the shortest residence time. These questions are further discussed in the next section, based on the results of numerical analysis.

\subsection{Results of numerical analyses and design guidelines}

This section describes the results obtained using the numerical analysis method presented in Section 3.1. In all simulations, all parameters were set to their default values, as listed in Table 1, except the parameter of which the effect is analysed. The effects of pipe geometry, processing capacity, air inlet conditions are successively presented, followed by the proposition of guidelines for the design of efficient pneumatic dryers.

\subsubsection{Effects of pipe geometry, dilution ratio and processing capacity}

The first result presented is the influence of pipe geometry, as this is one of the main interests of this paper. The model was used to simulate the variation of pipe diameter and assess its effect on the pipe length required to reach the target moisture and on the specific energy consumption of the dryer (using $\left[Q_{\mathrm{s}}, L_{\text {pipe }}\right]=f[D]$ ). Under default setting, the pipe diameter was varied from $0.145 \mathrm{~m}$ to $0.23 \mathrm{~m}$, which results in varying the starch dilution ratio

$\left(\frac{\dot{m}_{\mathrm{da}}}{\dot{m}_{\mathrm{ds}}}\right)$ from 9.6 to 24.2. The results are presented in Figure 3: 3a gives the energy consumption and the pipe length as a function of dilution ratio and $3 \mathrm{~b}$ gives the particle residence time as a function of pipe length. 
As expected, when increasing the starch dilution, the pipe length required for drying decreases, while the energy consumption increases linearly. The lowest energy consumption

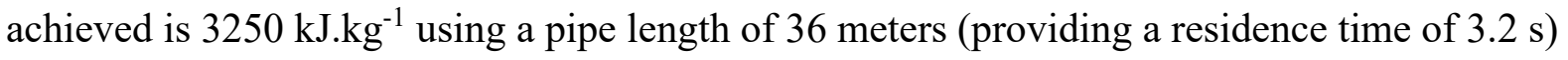
and a dilution ratio of 9.6. A long pipe provides a long residence time allowing the starch to dry with a limited air mass flow. In such conditions the air reaches the dryer outlet close to adiabatic saturation, so the energy available in the form of sensible heat is fully utilised. This clearly highlights the trade-off between pipe length and energy consumption. According to Figure 3a, under default settings, the pipe should be at least 25 meter-long (together with a dilution ratio of 11 or less) to ensure a specific energy consumption lower than $4000 \mathrm{~kJ} . \mathrm{kg}^{-1}$. This length corresponds to a residence time of $2.2 \mathrm{~s}$. For shorter pipes, the energy consumption increases sharply. Note that this trade-off partly determines the economic compromise between capital and operating costs: nevertheless as it also depends on several local factors, such as the prices of energy and raw materials, it was not included in the present study.

This result explains the difficulties faced by starch manufacturers trying to set up small capacity dryers. In most attempts, the pipe length used is shorter than $15 \mathrm{~m}$ and the air velocity in the range of $15-25 \mathrm{~m} \cdot \mathrm{s}^{-1}$. However, Figure 3a clearly shows that, in these conditions, the specific energy consumption cannot be below $6000-7000 \mathrm{~kJ} \cdot \mathrm{kg}^{-1}$ at best. By contrast, in most industrial dryers, the same air velocity range is used but with pipes longer than $40 \mathrm{~m}$, which explains that they achieve good energy efficiency.

Moreover, although this is not presented in the figures, a consequence of using short pipes with high dilution is to raise the temperature of starch, which may alter its quality. As an illustration, with the default configuration, the dilution ratio should be lower than 13 to keep the maximum temperature reached by the starch below $70^{\circ} \mathrm{C}$. Although the predicted starch 
temperature is approximate (due to the assumptions on heat transfer), this result explains the gelatinisation problems reported by the small starch producers.

Accordingly, using long pipes is crucial to ensure both the energy efficiency of the dryers and the quality of the product. It provides a long residence time allowing the starch to dry using a limited air flow (or dilution) while keeping its temperature low. The dilution ratio is physically limited by the quantity of water that the drying air can take up until saturation. In theory, the minimum air mass flow rate may be evaluated by considering that, at best, the drying air undergoes an adiabatic moistening up to saturation [35]. In the present case for instance, the adiabatic dilution ratio is 8.13 , while the lowest value reached in the simulation is 9.6 , i.e. $18 \%$ higher.

Eventually, another important finding is that the processing capacity has almost no influence on the dryer performance. Simulation were run using starch feed rate from $0.02 \mathrm{~kg} . \mathrm{s}^{-1}$ to $2 \mathrm{~kg} \cdot \mathrm{s}^{-1}$ and the results obtained were almost identical, though with a very small advantage for high-capacity dryers in terms of energy consumption in the higher range of pipe length. The consequence is that the design rules are the same for small and high capacity. Thus, the results in Figure 3 are valid for any processing capacity, and the same applies to all simulation results presented in the following sections.

\subsubsection{Effect of inlet air velocity}

Now that the influence of the geometry was analysed, the results of simulations are presented in the space of the objectives $\left(Q_{s}\right.$ vs. $\left.L_{p i p e}\right)$, thus the value of pipe diameter is not displayed (although it decreases with increasing pipe length). This method simplifies the illustration of the results, presenting them as Pareto fronts.

Figure 4 illustrates the results of simulations for three different inlet air velocities. Note that the case at $15 \mathrm{~m} \cdot \mathrm{s}^{-1}$ corresponds to the default configuration, already presented in the previous 
section. The inlet air velocity appears to have a strong effect on the required pipe length and the energy consumption; especially, increasing the air velocity increases the specific energy consumption at equal pipe length. This effect is particularly pronounced for short pipes but weakens rapidly for longer pipes. It is explained by the fact that air velocity directly affects the residence time, thus the required pipe length to dry a given amount of starch increases with increasing air velocity.

As an illustration, consider a $15 \mathrm{~m}$-long dryer; using an air velocity of $10 \mathrm{~m} . \mathrm{s}^{-1}$, it would be possible dry the starch to the target moisture with an energy consumption of about 4000 $\mathrm{kJ} . \mathrm{kg}^{-1}$, while it would cost about $7000 \mathrm{~kJ} \cdot \mathrm{kg}^{-1}$ at $15 \mathrm{~m} \cdot \mathrm{s}^{-1}$, and would not even be possible at $20 \mathrm{~m} \cdot \mathrm{s}^{-1}$. However, for dryers longer than $30 \mathrm{~m}$, these gaps are largely reduced. Indeed, in long dryers, the starch and air come closer to thermodynamic equilibrium and the drying rate is low in the last section of the pipe, making them less sensitive to velocity changes.

\subsubsection{Effects of air temperature}

Using the same method as for air velocity, the influence of air temperature were analysed and the results are presented in Figure 5. The simulations were conducted for 3 temperature levels, $140^{\circ} \mathrm{C}, 160^{\circ} \mathrm{C}$ and $180^{\circ} \mathrm{C}$. The result clearly shows the strong effect of this parameter: increasing the air temperature reduces the length required for drying and thus increases the energy efficiency at equal pipe length. This results from the intensification of mass transfer at high temperature. Increasing the air temperature also increases the particle temperature, which has mostly two effects: (i) increasing the diffusivity of water in starch and (ii) displacing the sorption by reducing the water activity at the surface of starch particles. Thereby, both the diffusivity and the concentration gradient are increased. As for air velocity and for the same reasons, the effect is less pronounced for long dryers. 
Increasing the air temperature may be an efficient way to limit the energy consumption of a dryer but to a limited extent, since gelatinisation problems may arise if the particle temperature exceeds $60^{\circ} \mathrm{C}$ during a too long period. For instance, in the simulation of dryer TH-2 presented in Figure 2, the starch reaches a maximum temperature of $62.5^{\circ} \mathrm{C}$, for an inlet temperature of $175^{\circ} \mathrm{C}$. Moreover, the air temperature is not the only factor; the starch temperature is also conditioned by the dilution ratio. For this reason, the air temperature should be carefully monitored and high temperatures should be avoided where the drying pipe is short and the dilution high.

\subsubsection{Effects of particle diameter}

At last, the effect of particle size was analysed and is presented in Figure 6, for diameters varying from $210 \mu \mathrm{m}$ to $270 \mu \mathrm{m}$. The effect is very similar to that of air temperature and velocity. The smaller the particles, the faster the drying. However, unlike air velocity and temperature, particle size is difficult to control. It is essential to use a good feeding system that enables the proper disaggregation of the starch cake when it enters the drying pipe. Otherwise, the only way to overcome the slow drying of large particles is to use a dryer with a long pipe.

Given the very small size and relatively low density of starch particles, the effect of particle size on residence time is negligible. Within the range of diameter considered here, the particles are all entrained by the airflow with a slip velocity of the order of $1 \mathrm{~m} \cdot \mathrm{s}^{-1}$. Moreover, it was also observed that the particle size has no influence on the temperature taken by the particles, at equivalent air mass flow rate (or dilution). Actually, the higher energy flux (per unit volume) received by small particles is compensated by the higher drying rate resulting from the faster diffusion, thus maintaining the particle temperature. 


\subsubsection{General design guidelines}

In this section, we synthesized the observations made from the previous results to provide general guidelines for the design of energy-efficient flash dryers. The first step is to choose the lowest acceptable air velocity. Among the industrial dryers considered in this work, dryer PA-2 uses the lowest air velocity at $10 \mathrm{~m} \cdot \mathrm{s}^{-1}$. However, this dryer also has pipe restriction to raise the air velocity where it reaches $8 \mathrm{~m} \cdot \mathrm{s}^{-1}$, suggesting that lower velocity might cause entrainment issues. Thus, if lower air velocities are to be used, experimental trials should be conducted to determine the threshold value. Anyway, according to Figure 3, by applying an air velocity of $10 \mathrm{~m} \cdot \mathrm{s}^{-1}$, energy-efficient dryers may be designed with relatively short pipes $\left(3350 \mathrm{~kJ} \cdot \mathrm{kg}^{-1}\right.$ at $\left.20 \mathrm{~m}\right)$.

Then, the air temperature should be chosen regarding the maximum allowed by the constraints on product quality. In the case of cassava starch, it is not recommendable to use air temperature higher than $180{ }^{\circ} \mathrm{C}$ since this may heat the starch particle over $60{ }^{\circ} \mathrm{C}$ and cause gelatinisation issues. It should also be considered that the use of temperature lower than $140^{\circ} \mathrm{C}$ considerably increases the dry time: thus, a long pipe will be required to achieve reasonable energy efficiency. Another factor that needs to be considered for the choice of the operating temperature is the gap between the inlet and target moisture content of the starch: if this gap is large, high temperature should be used.

Finally, the pipe diameter and length have to be defined. At this step, the question of the investment cost may be important, especially for small-scale dryers. As for most industrial equipment, economies of scale arise when increasing the capacity. For large-capacity dryer, long pipes may be easily affordable, enabling high energy efficiency (thus low operating cost) and providing a greater flexibility of operation. On the other hand, for small-capacity dryers, the investment cost may limit the possibility to use very long pipes. However, it is not 
advisable to build dryers shorter than 20-25 m: this would impose to use too high dilution, likely to cause gelatinisation issues and poor energy efficiency.

Then, choosing a diameter implies choosing a dilution ratio. The most convenient method would be to use the model presented here to estimate it. Without a model, it must be estimated based on the theoretical minimum, i.e. the mass flow rate that would produce adiabatically saturated exhaust air. This provides the lower bound for the dilution ratio, which should be increased by $15 \%$ to $50 \%$ depending on the chosen pipe length and temperature. If the chosen diameter is too low, the dryer will not reach the desired processing capacity; if is too large, it will be necessary to reduce either the air velocity (if possible) or the air temperature to avoid over-drying the starch. Therefore, in case of doubt, it is preferable to slightly oversize the diameter.

Eventually a design possibility, that was not investigated in the model, is the use of a drying pipe with variable diameter to improve the control of drying, product quality and energy performance. This technique is already implemented on industrial dryers, such as TH-2 and PA-2 presented in Table 1 or the Thermo Venturi Dryers proposed by MitchellDryers Ltd (Carlisle, Cumbria, UK). The drying material is fed into a venturi section at high air velocity to ensure good dispersion of the solids and help breaking larger particles. Then the pipe diameter is progressively enlarged to decrease the air velocity and provide suitable residence time.

\section{Conclusion}

A one-dimensional model was developed to describe the drying of particles in a pneumatic conveying dryer, following a water-diffusion-driven mechanism. For the first time, such a model was successfully applied to cassava starch drying to calculate the velocity, moisture and temperature profiles of particles and drying air along the tube, in steady-state operation. 
Simulations were run with field data from five industrial starch dryers, using the particle diameter as a fitting parameter. The range of fitted diameters was limited to $210-245 \mu \mathrm{m}$. The model outputs were consistent with the field data, in terms of product moisture and exhaust air temperature. The predicted drying profiles were relevant in terms of physical meaning and thus provided a good understanding of the drying process, although further experimental trials would be necessary to confirm their validity.

Then, a numerical analysis method based on a series of simulations was conducted to provide guidelines for the design of small-scale flash dryers. The results show that there is a marked trade-off between the dryer length and the energy consumption. The effect of pipe geometry, air inlet conditions and particle diameter were assessed. The scale (capacity) has a negligible effect on energy efficiency. The residence time, which is mostly determined by the pipe length and the air velocity, clearly appeared as the most influential factor and should be systematically maximised. The use of drying pipes longer than 25 meters allows to dry the

starch with a limited air mass flow rate (i.e. low dilution ratio), which is crucial to ensure (i) a good energy efficiency and (ii) to keep the product temperature low, preserving its quality. Finally the air temperature should be set to the maximum allowed by product quality constraints, as it improves the energy efficiency. The results of simulations brought a deeper insight into the mechanism of starch drying in pneumatic dryers. Despite numerous interactions, the relative influences of design variables were clarified and general design guidelines were proposed.

\section{Acknowledgement}

This work received the support from the CGIAR Research Program on Roots, Tubers and Bananas (RTB). Additionally, we would like to thank the members of the SEPO research 
group, and particularly Pr. Warinthorn Songkasiri and Dr. Kanchana Saengchan, from King Mongkut's University of Technology Thonburi, for the helpful discussions about the results.

\section{References}

1. Da, G., Dufour, D., Giraldo, A., Moreno, M., Tran, T., Velez, G., ... Marechal, P.-A. (2013). Cottage Level Cassava Starch Processing Systems in Colombia and Vietnam. Food and Bioprocess Technology, 6(8), 2213-2222. doi:10.1007/s11947-012-0810-0

2. Tonukari, N. J. (2004). Cassava and the future of starch. Electronic journal of biotechnology, 7(1), 5-8.

3. Sriroth, K., Piyachomkwan, K., Wanlapatit, S., \& Oates, C. G. (2000). Cassava Starch Technology: The Thai Experience. Starch - Stärke, 52(12), 439-449. doi:10.1002/1521379X(200012)52:12<439::AID-STAR439>3.0.CO;2-E

4. Balagopalan, C., Padmaja, G., Nanda, S. K., Moorthy, S. N., \& others. (2002). Cassava in food, feed, and industry. In Cassava: biology production and utilisation. (RJ Hillocks, JM Thresh, A Bellotti., pp. 301-318). CABI.

5. Mezhericher, M., Levy, A., \& Borde, I. (2010). Three-dimensional modelling of pneumatic drying process. Powder Technology, 203(2), 371-383.

doi:10.1016/j.powtec.2010.05.032

6. Radford, R. D. (1997). A model of particulate drying in pneumatic conveying systems. Powder Technology, 93(2), 109-126. doi:10.1016/S0032-5910(97)03237-3

7. Narimatsu, C. P., Ferreira, M. C., \& Freire, J. T. (2007). Drying of Coarse Particles in a Vertical Pneumatic Conveyor. Drying Technology, 25(2), 291-302.

doi:10.1080/07373930601119599

8. El-Behery, S. M., El-Askary, W. A., Hamed, M. H., \& Ibrahim, K. A. (2013). 
Eulerian-Lagrangian Simulation and Experimental Validation of Pneumatic Conveying Dryer. Drying Technology, 31(12), 1374-1387. doi:10.1080/07373937.2013.796483

9. Bhattarai, S., Oh, J.-H., Euh, S.-H., Kim, D. H., \& Yu, L. (2014). Simulation Study for Pneumatic Conveying Drying of Sawdust for Pellet Production. Drying Technology, 32(10), 1142-1156. doi:10.1080/07373937.2014.884575

10. Pelegrina, A. H., \& Crapiste, G. H. (2001). Modelling the pneumatic drying of food particles. Journal of Food Engineering, 48(4), 301-310. doi:10.1016/S0260-8774(00)001709

11. Tanaka, F., Uchino, T., Hamanaka, D., \& Atungulu, G. G. (2008). Mathematical modeling of pneumatic drying of rice powder. Journal of Food Engineering, 88(4), 492-498. doi:10.1016/j.jfoodeng.2008.03.014

12. Otuu, O. O., Omenyi, S., \& Nwigbo, S. (2013). Finite element modelling of cassava flash drying in a vertically upward pneumatic conveying dryer. Journal of Engineering and Applied Sciences, 9, 24-41.

13. Kemp, I. C., Bahu, R. E., \& Pasley, H. S. (1994). Model Development and Experimental Studies of Vertical Pneumatic Conveying Dryers. Drying Technology, 12(6), 1323-1340. doi:10.1080/07373939408961008

14. Kemp, I. C., \& Oakley, D. E. (2002). Modelling Of Particulate Drying In Theory And Practice. Drying Technology, 20(9), 1699-1750. doi:10.1081/DRT-120015410

15. Bimbenet, J.-J., Duquenoy, A., \& Trystram, G. (2002). Génie des procédés alimentaires: des bases aux applications. Dunod.

16. Aichayawanich, S., Nopharatana, M., Nopharatana, A., \& Songkasiri, W. (2011). Agglomeration mechanisms of cassava starch during pneumatic conveying drying. Carbohydrate Polymers, 84(1), 292-298. doi:10.1016/j.carbpol.2010.11.036 
17. Bird, R. B., Stewart, W. E., \& Lightfoot, E. N. (2007). Transport Phenomena. John Wiley \& Sons.

18. Conde, M. (2007). Thermophysical Properties of Humid Air: Models and Background. M. Conde Engineering, Zurich.

19. Green, D., \& Perry, R. (2007). Perry’s Chemical Engineers' Handbook (Eighth Edition.). McGraw Hill Professional.

20. Kreith, F., Timmerhaus, K., Lior, N., Shaw, H., Shah, R. K., Bell, K. J., \& et al. (2000). Applications. In The CRC Handbook of Thermal Engineering (Frank Kreith.). Boca Raton: CRC Press LLC.

21. Schiller, L., \& Naumann, Z. (1935). A drag coefficient correlation. Vdi Zeitung, 77(318), 51 .

22. Capes, C. E., \& Nakamura, K. (1973). Vertical pneumatic conveying: an experimental study with particles in the intermediate and turbulent flow regimes. The Canadian Journal of Chemical Engineering, 51(1), 31-38.

23. Rathore, M. M., \& Kapuno, R. R. (2011). Engineering Heat Transfer (2nd edition.). Burlington: Jones \& Bartlett Learning.

24. Crank, J. (1975). The mathematics of diffusion (2nd edition.). Oxford: Oxford University Press.

25. Karathanos, V. T., Vagenas, G. K., \& Saravacos, G. D. (1991). Water diffusivity in starches at high temperatures and pressures. Biotechnology Progress, 7(2), 178-184. doi:10.1021/bp00008a013

26. Al-Muhtaseb, A. H., McMinn, W. A. M., \& Magee, T. R. A. (2004). Water sorption isotherms of starch powders. Part 2: Thermodynamic characteristics. Journal of Food 
Engineering, 62(2), 135-142. doi:10.1016/S0260-8774(03)00202-4

27. Drouzas, A. e., \& Saravacos, G. d. (1988). Effective Thermal Conductivity of Granular Starch Materials. Journal of Food Science, 53(6), 1795-1799. doi:10.1111/j.13652621.1988.tb07845.x

28. Pakowski, Z., \& Mujumdar, A. S. (2006). 3 Basic Process Calculations. In Handbook of Industrial Drying (p. 51). CRC Press.

29. Levy, A., \& Borde, I. (2006). 17 Pneumatic and Flash Drying. In Handbook of Industrial Drying (p. 381). CRC Press.

30. Karathanos, V. T., \& Saravacos, G. D. (1993). Porosity and pore size distribution of starch materials. Journal of Food Engineering, 18(3), 259-280. doi:10.1016/02608774(93)90090-7

31. Marousis, S. n., \& Saravacos, G. d. (1990). Density and Porosity in Drying Starch Materials. Journal of Food Science, 55(5), 1367-1372. doi:10.1111/j.13652621.1990.tb03939.x

32. Gevaudan, A., Chuzel, G., Didier, S., \& Andrieu, J. (1989). Physical properties of cassava mash. International Journal of Food Science \& Technology, 24(6), 637-645. doi:10.1111/j.1365-2621.1989.tb00690.x

33. Al-Muhtaseb, A. H., McMinn, W. A. M., \& Magee, T. R. A. (2004). Water sorption isotherms of starch powders: Part 1: mathematical description of experimental data. Journal of Food Engineering, 61(3), 297-307. doi:10.1016/S0260-8774(03)00133-X

34. Ford Versypt, A. N., \& Braatz, R. D. (2014). Analysis of finite difference discretization schemes for diffusion in spheres with variable diffusivity. Computers \& Chemical Engineering, 71, 241-252. doi:10.1016/j.compchemeng.2014.05.022 
35. Strumillo, C., Jones, P. L., \& Zylla, R. (2006). 46 Energy Aspects in Drying. In Handbook of Industrial Drying. CRC Press.

36. Lee, D.-H., \& Kim, S.-D. (1993). Drying characteristics of starch in an inert medium fluidized bed. Chemical engineering \& technology, 16(4), 263-269.

37. Tasirin, S. M., \& Anuar, N. (2001). Fluidization Behavior of Vibrated and Aerated Beds of Starch Powders. Journal of chemical engineering of Japan, 34(10), 1251-1258.

38. Crowe, C. T., Schwarzkopf, J. D., Sommerfeld, M., \& Tsuji, Y. (2011). Multiphase Flows with Droplets and Particles, Second Edition. CRC Press. 